\title{
Mide kanserinde güncel durum: Lokalizasyon, patoloji ve yaş
}

\author{
The current status in gastric cancer: Localization, pathology, and age
}

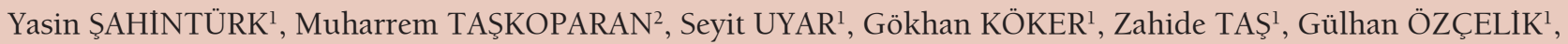
Ferda AKBAY HARMANDAR ${ }^{3}$, Ayhan Hilmi ÇEKIN ${ }^{3}$

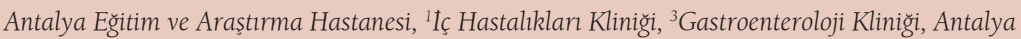

Özel Güven Hastanesi ${ }^{2}$ Gastroenteroloji Kliniği, Ankara

Giriș ve Amaç: Mide kanseri Dünya üzerinde en sık görülen ikinci kanser nedenli ölüm nedenidir. Batılı ülkelerde son ylllarda proksimal yerleşimli mide kanserlerinin arttığ bunun yanında distal yerleşimli mide kanseri görülme oranının düştügü rapor edilmektedir. Son zamanlarda ülkemizde tespit edilen mide kanserlerinin yerleşimi, patolojik tipi ve görülme yaşın tespit etmek amacıyla 2010-2015 yılları arasında tanı konulan mide kanser vakaları araștırıldı. Gereç ve Yöntem: Antalya Eğitim ve Araștırma Hastanesi ve Ankara Güven Hastanesi Gastroenteroloji Kliniklerinde 2010-2015 yılları arasında tanı almıs mide kanseri vakaları retrospektif olarak araștırıldı. Toplam 203 hasta çalışmaya dahil edildi. Hastalar 2010-2013 arası 1. grup 2013-2016 arası 2. grup olmak üzere iki gruba ayrıldı. Hastaların dosyalan retrospektif olarak incelenerek demografik özellikleri, mide kanserinin endoskopik tespit edilen yerleșimi ve patolojik değerlendirme sonuçlar iki grup arasında karşılaştırıldı. Bulgular: Hastaların 126'sı (\%62.1) erkek, 77'si (\%37.9) kadındı. Erkek ve kadın hastaların yas ortalamaları arasında istatistiksel fark tespit edilmedi $(p>0,05)$. Tüm hastalar incelendiğinde toplam 203 hastanın 68'i (\%33.5) proksimal, 135'i (\%66.5) distal mide kanser olarak saptand1. 2. grupta proksimal mide kanseri 1. gruba göre daha sik saptanmakla birlikte istatistiksel anlamlı düzeye ulaşmadı. Mide kanseri yerleșimleri ile hastaların yaşları ve cinsiyetleri arasında istatistiksel fark tespit edilmedi $(p>0,05) .154$ (\%75) hastada adenokanser, 25 (\%12) hastada karsinoid tümör, 15 (\%8) hastada lenfoma, 9 (\%5) hastada stromal tümör tespit edildi. Ikinci grupta istatistiksel anlamlı olmamakla birlikte 1.gruba göre daha sık karsinoid tümör saptandı. Patolojik kanser tipleri ile yas ve cinsiyet arasında istatistiksel olarak anlamlı bir fark bulunmadı $(p>0,05) .45$ yaş alt mide kanseri oranı tüm hastaların \%13.5'unu olușturmaktaydı. Sonuç: Mide kanserleri en çok mide korpusu sonra antrum ve en az sıklıkta kardiyada görülmektedir. Bulgularımız son yıllarda rapor edilen proksimal mide kanserinin distal mide kanserinden daha sık görüldüğü sonucuyla çelişmekle birlikte proksimal mide kanserinin insidansının artış eğiliminde olduğunu göstermektedir. Mide kanseri tespit edilen genç hastaların çokluğu ve hatta 20'li yaşlarda hastaların tespit edilmesi nedeniyle dispeptik hastalarda endoskopi istemlerinde yaş sinırlarının gözden geçirilmesi gerektiğini düşündürmektedir.

Anahtar kelimeler: Mide kanseri, proksimal, distal, patoloji, yaş

\section{GİRIS}

Mide kanseri kanser nedenli ölümler arasında ikinci sıradadır. Gelişmiş ülkelerde son yıllarda sıklığı azalma eğilimi gösterse de gelişmekte olan ülkelerde ve mide kanserinin endemik olduğu ülkelerde görülme sılklı̆ı artmaktadır. Son 30 yılda yapılan bir çok çalışmada proksimal gastrik kanser (PGK) insidansında artış olduğu bildirilmiştir $(1,2)$. Amerikan ulusal kanser verileri de bu durumu destekler niteliktedir ve gastrik

Sahintürk Y, Taşkoparan M, Uyar S, et. al. The current status in gastric cancer: localization, pathology, and age. Endoscopy Gastrointestinal 2016;24:61-64.
Background and Aims: Gastric cancer is the second most common cancer-related cause of death throughout the world. It is reported that in recent years, proximal gastric cancer cases have increased, and distal gastric cancer cases have decreased in western countries. We searched for the newly-diagnosed gastric cancer cases between 2010 and 2015 in order to determine the localization, pathology, and age status of the patients. Materials and Methods: Gastric cancer cases diagnosed between 2010 and 2015 in the Antalya Training and Research Hospital and the Ankara Güven Hospital were retrospectively evaluated. A total of 203 patients were included in the study. The patients were divided into two groups according to the year of diagnosis, the first group being diagnosed between 2010 and 2013 and the second one, between 2013 and 2016. These two groups were compared according to the localization and pathology of the tumor and the age of the patients. Results: From the total, 126 (62.1\%) patients were male, and 77 (37.9\%) were female. There was no statistically significant difference between the mean age of the male and female patients ( $p>0.05)$. A total of 203 patients were studied and 68 (33.5\%) were diagnosed as having proximal and 135 (66.5\%) as having distal gastric cancer. [Editor1][J2] Proximal gastric cancer cases were more frequent in the second group, but this was not statistically significant. The age and sex showed no difference according to the localization of the gastric cancer ( $p>0.05)$. $154(75 \%)$ adenocancer, 25 (12\%) carcinoid tumor, 15 (8\%) lymphoma, and 9 (5\%) stromal tumor cases were detected. Carcinoid tumor cases were more frequent in the second group, but this was not statistically significant. The age and sex showed no difference according to the pathological type of the gastric cancer $(p>0.05)$. The rate of stomach cancer under the age of 45 constituted $13.5 \%$ of all of the patients. Conclusion: Gastric cancer is mostly seen in the corpus, then in the antrum, and least in the cardia. Our results are inconsistent with the recent studies showing a proximal gastric cancer dominancy, but we showed an upward trend for the proximal gastric cancer. The age limit for an endoscopy in dispeptic patients should be revised because of an increase in the young, even in their 20s, patients with gastric cancer.

Key words: Gastric cancer, proximal, distal, pathology, age

kanserlerin yaklaşı \% 50'sinin kardiya ya da fundus kaynaklı olduğu bildirilmiştir (3).

Çalışmalarda PGK'nın distal gastrik kansere (DGK) göre daha kötü prognoza sahip olduğu gösterilmiş ve bu durum PGK'nin farklı klinik ve biyolojik davranış göstermesine bağlanmıştır (4). Özellikle obezitenin $(3,5)$ ve sigara kullanımının $(6,7)$ 
PGK gelişiminde önemli iki risk faktörü olduğu düşünülmektedir. Proksimal gastrik kanser tespit edilen hastalarda vucut kitle indeksi (VKI) değerlerinin distale göre anlamlı derecede daha yüksek olduğu saptanmıştır (3). DGK gelişiminde ise Helicobacter pylori (H. pylori) grup 1 karsinojen olarak nitelenmektedir ve eşlik eden aşırı tuz, sigara ve alkol kullanımının da bu riski artırdığı bilinmektedir (8). Bu durumun aksine $H$. pylori enfeksiyonunun proksimal gastrik kanser için koruyucu olduğu yönünde veriler mevcuttur. H. pylori enfeksiyonuna bağlı gelişebilen ciddi atrofik gastrit ya da mide asiditesinin azalması gastroözofajiyal reflüyü (GÖR) azaltarak proksimal gastrik kanser gelişmesini engellediği düşünülmektedir (8).

Türkiye'de obezite, sigara kullanımı ve bunlara eşlik eden GÖR sıklığının artmasının PGK sıklığını arttıracağı düşünülmekle birlikte Türkiye'de yapılan son çalışmalarda bile \%60'lara varan H. pylori prevalansı ve eradikasyonda yaşanan zorluklar (9) DGK-PGK insidanslarının değişim trendlerinin Asya-Avrupa-Amerika kaynaklı verilerle aynı doğrultuda olmayabileceğini düşündürtmektedir. Çalışmamızda son zamanlarda ülkemizde tespit edilen mide kanserlerinin yerleşimi, patolojik tipi ve görülme yaşını tespit etmek amacıyla Antalya Eğitim ve Araştırma Hastanesi ve Ankara Güven Hastanesi Gastroenteroloji Kliniklerinde 2010-2015 yılları arasında tanı konulan mide kanseri vakaları araştırıldı.

\section{GEREÇ ve YÖNTEM}

Antalya Eğitim ve Araştırma Hastanesi ve Ankara Güven Hastanesi Gastroenteroloji Kliniklerinde 2010-2015 ylları arasında tanı almış mide kanseri vakaları retrospektif olarak araştırıldı. Toplam 10.763 endoskopinin patoloji raporları retrospektif olarak tarandı. Toplamda 203 hasta çalışmaya dahil edildi. Hastaların dosyaları incelenerek hastaların demografik özellikleri, mide kanserinin endoskopik tespit edilen yerleşimi ve patolojik değerlendirme sonuçları kaydedildi. Ayrica hastalar endoskopileri 2010-2013 arası yapılanlar grup 1 ve 2013-2015 arası yapılanlar grup 2 olmak üzere iki gruba ayrıldı ve bu gruplar hastaların demografik özellikleri, mide kanserinin endoskopik tespit edilen yerleşimi ve patolojik değerlendirme sonuçları açısından karşılaştırıldı. Endoskopik olarak korpus ilk 1/3 kesim proksimal, son 2/3 kesim ise distal mide kanseri olarak kabul edildi.

Çalışmadan elde edilen bulguların değerlendirilmesinde istatistiksel analizler için SPSS (Statistical Package for Social Sciences) for Windows 16.0 programı kullanıldı. Tanımlayı$\mathrm{cl}$ istatistiksel metodların [ortalama \pm standart sapma, ortanca (range)] yanı sıra, niceliksel verilerin bağımsız iki grup arası karşılaştırmasında Student t testi kullanıldı. Süreklilik gösteren değişkenlerin normal dağılıma uygunluğu tek örneklem Kolmogorov-Smirnov Testi ile araştırıldı. Niteliksel verilerin gruplar arası karşılaştırmalarında Ki-Kare testi veya Fisher'in tam olasılık testleri kullanıldı. Korelasyon analizlerinde pa- rametrelerin dağılımına göre Pearson korelasyon analizi veya Spearman korelasyon analizi kullanıldı. Sonuçlar \%95'lik güven aralığında, anlamlılık p<0.05 düzeyinde ifade edildi.

Çalışmamız Helsinki Deklarasyonu prensiplerine uygun olarak yapılmış, ilgili hastanelerin etik kurullarından onay alınmış ve çalışmaya katılan hastalardan bilgilendirilmiş olur alınmıştır.

\section{BULGULAR}

2010-2013 yılları arasında endoskopi yapilan 95 hastanın 65’i $(\% 68,4)$ erkek, 30’u $(\% 31,6)$ kadind. Erkek hastaların yaş ortalaması $60,95 \pm 14,23$ kadınların yaş ortalaması $62,1 \pm 16,24$ olarak bulundu. Erkek ve kadın hastaların yaş ortalamaları arasında istatistiksel fark tespit edilmedi (P>0,05). En genç hasta 27 yaşında, en yaşlı hasta 86 yaşında kadın olarak bulundu. Mide kanserlerinin yerleşimleri: Kardiya 18 (\%18,9), korpus $49(\% 51,6)$, antrum 28 (\%29,5) şeklindeydi. 28 (\%29.4) hasta proksimal mide kanseri olarak değerlendirildi (Tablo 1). Mide kanseri yerleşimleri ile hastaların yaşı ve cinsiyetleri arasında istatistiksel fark tespit edilmedi $(P>0,05)$. Hastalarm 59'unda $(\% 62,1)$ intestinal tipte adenokanser, 15 'inde $(\% 15,8)$ diffüz adenokanser, $9(\% 9,5)$ hastada karsinoid tümör, $7(\% 7,4)$ hastada stromal tümör ve $5(\% 5,3)$ hastada lenfoma tespit edilmiştir (Tablo 2). Patolojik kanser tipleri ile yaş ve cinsiyet arasında istatistiksel olarak anlamlı bir fark bulunmamıştır ( $\mathrm{P}>0,05)$. 65 yaş üstü yaşlı hastalar ile 65 yaş altı hastaların mide kanseri yerleşimi ve patolojik tipleri açısından farklı olmadıkları bulundu (P>0,05). 45 yaş altında $15(\% 15,8)$ hasta olması ve bunların $10(\% 10,5)$ tanesinin 30'lu yaşlarda olduğu tespit edildi. İki $(\% 2,1)$ hastada erken mide kanseri tespit edilmişti.

2013-2016 yılları arasında endoskopi yapılan 108 hastanın yaşları 26 ile 91 arasında değişmekte olup hastaların 47'si kadın (\%43.5), 6l'i erkek (\%56.5), kadın/erkek oranı 0.77'ydi. Mide kanserlerinin yerleşimleri: kardiya 31 (28.7), korpus 42 (\%38.9), antrum 35 (32.4) şeklindeydi. 40 (\%37) hasta proksimal mide kanseri olarak değerlendirildi (Tablo 1). 80 hastada adenokarsinom (\%74.1), 16 hastada karsinoid tümör (\%14.8), 10 hastada lenfoma (\%9.3), 2 hastada gastrointestinal stromal tümör (\%1.8) saptandı (Tablo 2). Kadın ve erkek hastalar arasında yaş ortalamaları açısından istatistiksel anlamlı farklılık saptanmadı. (p:0.486). Benzer şekilde, kadın ve erkek hastalar arasında, kanser yerleşimi ve tümörlerin histopatolojik tipleri açısından anlamlı farklılık saptanmadı ( $\mathrm{p}>0.05)$. Hastaların yaş dağılımı incelendiğinde, 45 hasta (\%41.66) 65 yaş ve üstü, 63 hasta (\%58.33) 65 yaş altını oluşturmaktaydı. 65 yaş ve üstü grubun kadın/erkek oranı 0.8, 65 yaş altı grubun kadın/erkek oranı 0.75 olup; cinsiyet dağılımı açısından anlamı farklılık bulunmadı ( $\mathrm{p}=0.87)$. Hastaların 13 tanesinin (\%12.03) 45 yaş altında olduğu saptandı. 45 yaş altı grubun kadın/erkek oranı 3.33, 45 yaş ve üstü grubun kadın/ 
erkek oranı 0.637 olup, cinsiyet dağılımı açısından istatistiksel anlamlı farklılık dikkati çekmekteydi $(\mathrm{p}=0.01)$.

Tüm hastalar incelendiğinde endoskopik mide kanseri saptama oranımız \%2 idi. Toplam 203 hastanın 68'i (\%33.5) proksimal, 135'i (\%66.5) distal mide kanseri olarak saptand. Mide kanserleri en çok mide korpusu sonra antrum ve en az siklıkta kardiyada görülmekteydi. Hastalar proksimal ve distal mide ca olarak karşılaştırıldığında her iki grupta distal mide ca daha sık saptandı. Kardiya ve proksimal mide kanseri ikinci grupta birinci gruba göre daha sık saptandı fakat bu artış trendinin istatistiksel olarak anlamlı olmadığı gözlendi $(\mathrm{p}=0.319)$ (Tablo 1). Adenokanser alt grubunun lokalizasyonu ile ilgili yapılan karşılaştırmada ise proksimal adenokanser ikinci grupta daha sık görülmekteydi (\%28.5 vs \%35) fakat istatistiksel anlamlı düzeyde değildi ( $\mathrm{p}=0.378$ ) (Tablo 3). Benzer şekilde karsinoid tümörlerde de bir artış trendi olduğu fakat bu artışın istatistiksel anlama ulaşmadığı saptandı $(\mathrm{p}=0.351) .6$ yıllık süreçte adenokanser tanısı alan hasta sayımiz 154 (\%75) olarak tespit edildi (Tablo 2).

Tablo 1. Mide ca yerleşim bölgeleri

\begin{tabular}{lccc} 
& Grup 1 & Grup 2 & $p$ \\
\hline Hasta sayısı & 95 & 108 & \\
\hline Erkek & $65(\% 68.4)$ & $61(\% 56.5)$ & 0.109 \\
\hline Proksimal mide ca & $28(\% 29.4)$ & $40(\% 37)$ & 0.319 \\
\hline Distal mide ca & $67(\% 70.6)$ & $68(\% 63)$ & 0.319 \\
\hline Kardiya & $18(\% 18,9)$, & $31(28.7)$ & 0.143 \\
Korpus & $49(\% 51,6)$ & $42(\% 38.9)$ & 0,094 \\
Antrum & $28(\% 29,5)$ & $35(32.4)$ & 0.769
\end{tabular}

Tablo 2. Mide ca patoloji sonuçları

\begin{tabular}{lccc} 
& Grup 1 & Grup 2 & p \\
\hline Hasta sayısı & 95 & 108 & \\
Adenokanser & $74(\% 77.9)$ & $80(\% 74.1)$ & 0.641 \\
Karsinoid & $9(\% 9.5)$ & $16(\% 14.8)$ & 0.351 \\
GIST & $7(\% 7.4)$ & $2(\% 1.8)$ & 0.111 \\
Lenfoma & $5(\% 5.3)$ & $10(\% 9.3)$ & 0.414
\end{tabular}

GIST: Gastrointestinal stromal tümör

\section{Tablo 3. Adenokanser lokalizasyonu}

\begin{tabular}{|lccc} 
& Grup 1 & Grup 2 & p \\
\hline Hasta sayısı & 74 & 80 & \\
\hline Proksimal adeno ca & $21(\% 28.5)$ & $28(\% 35)$ & 0.378 \\
\hline Distal adeno ca & $53(\% 71.5)$ & $52(\% 65)$ & \\
\hline
\end{tabular}

\section{TARTIŞMA}

Mide kanseri insidans ve mortalitesinde yaşanan ciddi düşüşe rağmen akciğer kanserinden sonra ikinci en sık kansere bağlı ölüm nedenidir (1). Türkiye'de yapılan çalışmalarda mide kanseri sıklığı Düzce yöresinde yapılan endoskopik incelemelerde \%2.3 (10), Van \%6.3 (11), Erzurum, Ankara ve Şanlıurfa yöresinde mide kanseri oranları sırasıyla \%4.8, \%2.2, \%2 olarak saptanmıştır (12). Çalışmamızda saptadığ1mız \%2 endoskopik mide kanseri saptama oranımı literatür ile uyumludur. Hastaların ortalama yaş ve cinsiyet dağılımı dikkate alındığında da literatür ile benzer şekilde erkek hasta dominansı ve 60 yaşından sonra mide kanseri insidansında artış saptadık (12-14). 2006 yılında yapılmış bir çalışmada 45 yaş altı mide kanseri saptanan olgular, tüm olguların \% 7'siyken (14) çalışmamızda \%13.5 bulunan bu oran zaman içinde mide kanseri görülme yaşının düştügünü göstermektedir. Bunun nedeni olarak aile öyküsü ya da genetik faktörlerin etkin rol oynayabileceğini düşünmekteyiz. Özellikle 2 hastada tespit ettiğimiz erken mide kanseri de bu tabloyu destekler niteliktedir. 45 yaş altı hastalarımızda dikkat çeken bir diğer özellik ise mide kanserinin kadın erkek oranının 45 yaş üstüne göre istatistiksel anlamlı düzeyde kadınlarda daha yüksek saptanmasıdır (kadın/erkek: 3.33, p=0.01). Bulgularımıza benzer şekilde Kore'de 45 yaş altı 3.342 genç mide kanseri tanılı hastayla yapılan çalışmada, 30 yaş altı grupta kadın/erkek: 2 saptanırken 30-40 yaş aralığındaki grupta ise bu oran 1.6 olarak saptanmıştır (15).

Patoloji sonuçlarımız incelendiğinde adenokanser sıklığının azaldığını ve gastrik karsinoidlerin artma eğiliminde olduğunu görmekteyiz. H. pylori eradikasyonunun gastrik adenokanser gelişimini azaltan en önemli faktör olduğu bilinmektedir. Gastrik karsinoidlerin görülme sılklı̆ının \%9.5'dan \%14.5’a artması ise aşırı proton pompa inhibitörü (PPI) kullanımına bağlanabilir (16). 2013 yılında Özer ve arkadaşları tarafından yayınlanan bir derlemede karsinoid tümör nadir görülmekle birlikte son 30 yılda insidansında anlamlı artış olduğu belirtilmiştir. PPI kullanan hastalardaki hipergastrineminin gastrik enterokromaffin-benzer hücrelerde hiperplaziye neden olduğu düşünülmekle birlikte uzun süreli PPİ kullanan, $H$. pylori pozitif gastrik atrofi ve mukozal inflamasyonu olan hastaların \%10-30'unda enterokromaffin-like hücre hiperplazisi görülebileceği vurgulanmıştır (16).

Son yıllarda midenin distal kismından (korpus ve antrum) kaynaklanan kanserlerin insidansı azalırken, proksimal mide ve özofagogastrik bileşkeden orijinini alan kanserlerin sıklığının arttığı bildirilmektedir. Bu artışın belirgin olarak proksimal gastrik adenokanser yönünde olduğu belirtilmiştir $(1,2,8,13,14)$. Batı tipi beslenmenin, alkol tüketiminin artmasının ve obezitenin daha sık görülmesinin proksimal 
mide kanserinin görülme sıklı̆̆ını artırıcı faktörler olduğu gözlenmiştir. H. pylori'nin tespit edilmesi ile birlikte mide kanserinin etiyoloji ve patogenezinin anlaşılması konusunda çığır açılmıştır. CagA virulans faktörü adenokanser ile sıkı korelasyon göstermektedir. H. pylori kronik gastrite yol açarak başlattığı patolojik süreci atrofik gastrit/intestinal metaplaziye kadar ilerletebilmektedir. Gelişen hipoasidite ise reflü semptomlarının da azalmasına yol açarak proksimal gastrik kanser görülme riskini azaltmakta ve atrofik zeminde distal gastrik kanser gelişme riskini artırmaktadır (17). Sonuçlarımızda distal gastrik kanserin halen daha sık görülüyor olması son yılların literatür verileri ile çelişmekle birlikte, proksimal gastrik kanserin ve alt grup analizinde proksimal gastrik adenokanserin 2. grupta daha sık görülmesi sıklığında bir artış trendinin olduğuna dikkat çekmektedir. Çalışmamızı yaptığımız Antalya-Ankara bölgesinde de batı tipi beslenme, alkol tüketimi ve obezitenin artmış olması da proksimal gastrik kanser gelişimini etkileyen diğer faktörler olarak düşünülebilir.

Sonuç olarak mide kanseri en çok mide korpusu sonra antrum ve en az sıklıkta kardiyada görülmektedir. Bulgularımız son yıllarda rapor edilen proksimal kanserlerin daha sık görüldüğü sonucuyla çelişmekle birlikte proksimal mide kanserinin insidansının artış trendinde olduğunu göstermektedir. $\mathrm{Bu}$ artış istatistiksel olarak anlamlı olmasa da konuyla ilgili daha yüksek hasta sayısıyla çalışmalar yapılırsa anlamlı sonuçlar elde edilebileceği düşüncesindeyiz. Değişen çevresel etkenlerin mide kanserinin lokalizasyonu dışında, patolojik tipini ve görülme yaşını da etkilediğini düşünmekteyiz. Mide kanseri tespit edilen genç hastaların çokluğu ve hatta 20'li yaşlarda hastaların tespit edilmesi dispeptik hastalarda endoskopi istemlerinde yaş sinırlarının gözden geçirilmesi gerektiğini düşündürtmektedir.

\section{KAYNAKLAR}

1. Blot WJ, Devesa SS, Kneller RW, Fraumeni JF Jr. Rising incidence of adenocarcinoma of the esophagus and ngastric cardia. JAMA 1991;265:1287-9.

2. Pera M, Cameron AJ, Trastek VF, et al. Increasing incidence of adenocarcinoma of the esophagus and esophagogastric junction. Gastroenterology 1993;104:510-3.

3. Hundahl SA, Phillips JL, Menck HR. The National Cancer Data Base Report on poor survival of US gastric carcinoma patients treated with gastrectomy: Fifth Edition American Joint Committee on Cancer staging, proximal disease, and the "different disease" hypothesis. Cancer 2000;88:921-32.

4. Qiu MZ, Cai MY, Zhang DS, et al. Clinicopathological characteristics and prognostic analysis of Lauren classification in gastric adenocarcinoma in China. J Transl Med 2013;11:58.

5. Chou HH, Kuo CJ, Hsu JT, et al. Clinicopathologic study of node-negative advanced gastric cancer and analysis of factors predicting its recurrence and prognosis. Am J Surg 2013;205:623-30.

6. Lagergren J, Bergstrom R, Lindgren A, Nyren O. The role of tobacco, snuff and alcohol use in the aetiology of cancer of the oesophagus and gastric cardia. Int J Cancer 2000;85:340-6.

7. Carr JS, Zafar SF, Saba N, et al. Risk factors for rising incidence of esophageal and gastric cardia adenocarcinoma. J Gastrointest Cancer 2013;44:143-51.

8. Guggenheim DE, Shah MA. Gastric cancer epidemiology and risk factors." J Surg Oncol 2013;107:230-6.

9. Çiftel S, Okçu N, Dursun H, et al. Bölgemizde Helicobacter pylori sıklığl. Akademik Gastroenteroloji Dergisi 2016;15:1-4.

10. Tamer A, Korkut E, Korkmaz U, Akcan Y. Üst gastrointestinal endoskopi sonuçları: Düzce Bölgesi. Kocatepe Tıp Dergisi 2005;6:31-4.

11. Tuncer 1, Uygan I, Kösem M, et al. Van ve çevresinde görülen üst gastrointestinal sistem kanserlerinin demografik ve histopatolojik özellikleri. Van Tip Dergisi 2001;8:10-13.

12. Nazlıül Y, Uslusoy H, Yılmaz N, et al. Şanlıurfa yöresinde üst gastrointestinal endoskopi bulguları ve Helicobacter pylori pozitifliği. Van Tıp Dergisi 1999;6(3):1-3.

13. Mansfield PF, Yao JC, Crane CH. Proximal Gastric Cancer. In: Holland-Frei Cancer Medicine. 6th edition. Kufe DW, Pollock RE, Weichselbaum RR, et al, editors. Hamilton (ON): BC Decker; 2003.

14. Crew KD, Neugut AI. Epidemiology of gastric cancer. World J Gastroenterol 2006;12:354-62.

15. Chung HW, Noh SH, Lim JB. Analysis of demographic characteristics in 3242 young age gastric cancer patients in Korea. World J Gastroenterol 2010;16:256-63.

16. Özer B. Uzun süreli proton pompa inhibitörü kullanımı ve pantoprazolün 15 yıllık çalışma sonuçları. Iç Hastalıkları Dergisi 2013;20:55-63.

17. Kelley JR, Duggan JM. Gastric cancer epidemiology and risk factors. J Clin Epidemiol 2003;56:1-9. 